\title{
Review of: "Numerical computation of 3D Brownian motion of thin film nanofluid flow of convective heat transfer over a stretchable rotating surface"
}

Mehdi Fakour

Potential competing interests: The author(s) declared that no potential competing interests exist.

\footnotetext{
Hope you are doing well,

I reviewed manuscript carefully and in my view the results of this manuscript is valuable.

This manuscript is acceptable after minor revision.

Comment No. 1: This paper should be edited grammatically.

Comment No. 2: It should be better that manuscript has a nomenclature.

Comment No.

Comment No. 3: Some important related papers must be included:

- Heat transfer and fluid flow of blood with nanoparticles through porous vessels in a magnetic field: A quasi-one-dimensional analytical approach, Mathematical Biosciences, Vol 283, pp. 38-47, 2017.

- Analytical study of micropolar fluid flow and heat transfer in a channel with permeable walls, Journal of Molecular Liquids, 204, 198-204, 2015.

- Scrutiny of underdeveloped nanofluid MHD flow and heat conduction in a channel with porous walls, International journal of Case Studies in Thermal

Engineering, 4,2014.

- Study of heat transfer and flow of nanofluid in permeable channel in the presence of magnetic field, Propulsion and Power Research, Volume 4, Issue 1, March 2015, Pages 5062.

- Study of heat transfer in nanofluid MHD flow in a channel with Permeable walls, begellhouse, Heat Transfer Research, 48(3), 221-238, 2017.

- Nanofluid thin film flow and heat transfer over an unsteady stretching elastic sheet by LSM, Journal of mechanical science and technology 32 (1), 177-183, 2018.

The paper is acceptable, but only after the above comments are suitably addressed. I shall proofread the final version.
} 